\title{
Modelling the potential geographic distribution of Trissolcus japonicus: a biological control agent of the brown marmorated stink bug, Halyomorpha halys
}

\author{
G. A. Avila · J. G. Charles
}

Received: 5 October 2017 / Accepted: 2 January 2018/Published online: 5 January 2018

(C) The Author(s) 2018, corrected publication March 2018

\begin{abstract}
Trissolcus japonicus Ashmead (Hymenoptera: Scelionidae) is an endoparasitoid of the eggs of the brown marmorated stink bug, Halyomorpha halys Stål (Hemiptera: Pentatomidae), a major agricultural pest native to China, Japan, South Korea and Taiwan. We used CLIMEX to estimate the potential global distribution of $T$. japonicus with particular reference to New Zealand. In its native range the model predicts the presence, or a potential expansion, of $T$. japonicus into most of humidsubtropical and humid-continental areas. Globally, the model projects that many temperate, Mediterranean and subtropical areas could suit the establishment of T. japonicus. In New Zealand, the north appears moderately to highly suitable for $T$. japonicus,
\end{abstract}

Handling Editor: Stefano Colazza

Electronic supplementary material The online version of this article (https://doi.org/10.1007/s10526-018-9866-8) contains supplementary material, which is available to authorized users.

G. A. Avila $(\bowtie)$. J. G. Charles

The New Zealand Institute for Plant \& Food Research Limited, Private Bag 92169, Auckland 1142,

New Zealand

e-mail: Gonzalo.Avila@plantandfood.co.nz

URL: http://www.b3nz.org

G. A. Avila · J. G. Charles

Better Border Biosecurity, Wellington, New Zealand

URL: http://www.b3nz.org while southern regions are mostly marginal. The risk posed by $T$. japonicus to non-target species in New Zealand is predicted to vary between different nontargets. CLIMEX projections of the potential distribution of $T$. japonicus provide guidance for release sites of this parasitoid if approved for importation and release in New Zealand.

Keywords Bioclimatic model - CLIMEX - Climate matching $\cdot$ Scelionidae $\cdot$ Pentatomidae $\cdot$ Parasitoid

\section{Introduction}

The brown marmorated stink bug, Halyomorpha halys Stål (Hemiptera: Pentatomidae), is a temperate/subtropical invasive species native to China, Japan, South Korea and Taiwan (Lee et al. 2013). It has a broad host range of more than 300 plant species (Lee et al. 2013; Bergmann et al. 2016), many of which are of economic importance, especially within the Fabaceae, Rosaceae and Solanaceae, but also including Poaceae, Rutaceae, Vitaceae and Actinidiaceae (Zhang et al. 2000; Yang et al. 2009; Lee et al. 2013; Bergmann et al. 2016). Halyomorpha halys has invaded the United States, Canada, and a number of European countries from its Asian homeland, and has become a major pest in some regions and crops (Haye et al. 2015; Leskey and Nielsen 2018). Most recently, in early 2017, $H$. halys was detected for the first time in South America 
in Chile (Faúndez and Rider 2017). In New Zealand, $H$. halys has been repeatedly intercepted at the border and is recognised as a major threat to New Zealand's economy and environment. Biosecurity authorities acknowledge that there is a high risk of establishment in New Zealand as a result of the numerous interceptions and the ability of $H$. halys adults to disperse quickly over long distances (Duthie 2012). A recently published CLIMEX model, which predicts the potential global geographical distribution of $H$. halys (Kriticos et al. 2017), estimates that, in New Zealand, most of the North Island and a number of areas in the northern and eastern sides of the South Island are suitable for the establishment of $H$. halys. If (or when) $H$. halys does establish in New Zealand, then successful biological control by natural enemies could provide a key management tool in concert with specific crop pest management programmes. Effective natural enemies will act in both managed and unmanaged habitats across New Zealand's landscapes.

Trissolcus japonicus Ashmead (Hymenoptera: Scelionidae) [syn. Trissolcus halyomorphae Yang; Talamas et al. (2013)] is a solitary endoparasitoid of the eggs of $H$. halys in its native range, and like this host, also overwinters as an adult, indicating a close synchrony between the two species (Nystrom Santacruz et al. 2017; Zhang et al. 2017). The minimum threshold temperature for development of T. japonicus was estimated to be $12.2^{\circ} \mathrm{C}$, with a thermal constant of 132.5 degree-days (Qiu et al. 2007). These parameters suggest that $T$. japonicus could potentially have up to ten generations per year in Beijing, China (Qiu et al. 2007). Female T. japonicus lay 42 eggs on average and prefer to oviposit in eggs no older than 1-3 days (Qiu et al. 2007). Yang et al. (2009) concluded that $T$. japonicus has the characteristics of an excellent biocontrol agent, including a high femaleto-male ratio, short developmental time, and many more generations than its host. Yang et al. (2009) also found that $T$. japonicus could successfully parasitize the eggs of a few other species of pentatomid pests in laboratory mass rearings, and they suggested that such alternative hosts may help support high population levels of the parasitoids in China. Zhang et al. (2017) also collected $T$. japonicus from several native Pentatomidae species in China, indicating that the parasitoid is oligophagous within the Pentatomidae in its native range.
When a biological control agent is introduced into a new location, it needs to be able to persist and thrive in the climatic conditions of its new environment (Robertson et al. 2008; van Driesche et al. 2008). Natural enemies obtained from areas with similar climatic conditions to the recipient area are generally more likely to succeed in achieving effective control (Hoelmer and Kirk 2005). Conversely, when climatic mismatch occurs between both the donor and the recipient area, it is frequently considered to be responsible for the failure of establishment, or low effectiveness in controlling the target pest (Hoelmer and Kirk 2005; Dhileepan et al. 2006). As part of a classical biocontrol programme, climatic modelling can help to quantify the similarity of climatic conditions between invaded areas and the native range of the invasive species. Using this information it is possible to find the areas with the best climatic match to search for and collect natural enemies (van Driesche et al. 2008). This method improves the chance of establishment when releasing natural enemies in the recipient country (Hoelmer and Kirk 2005; Dhileepan et al. 2006), thus improving the success of biocontrol programmes (Sutherst 2003). Climate plays an important role in limiting the potential geographical distribution of species (Kriticos et al. 2012), and, as such, climatic variables have been widely used to predict the potential distribution of invasive alien species as part of risk assessments (Saavedra et al. 2015; Kriticos et al. 2017), and also of natural enemies used in biocontrol programmes (Robertson et al. 2008; Olfert et al. 2016).

Niche modelling is often used to estimate areas with suitable climatic conditions for the survival of species (Anderson et al. 2003). A number of bioclimatic modelling software (e.g. CLIMEX, BIOCLIM, DOMAIN) have been widely used in biocontrol (Dhileepan et al. 2006; Olfert et al. 2016) or in pest risk assessment (Baker et al. 2000; Sutherst 2014) to estimate the similarity of climatic conditions between the home range and the receiving range of an invasive species. CLIMEX is a well-recognised climate modelling software that was designed with biological control applications in mind (Kriticos et al. 2015a). It has been widely used to estimate the potential distribution of insect pests (Kriticos et al. 2007; Saavedra et al. 2015), weeds (Potter et al. 2009; Watt et al. 2011), diseases (Yonow et al. 2004; Watt et al. 2009), and natural enemies (Mo et al. 2000; Olfert 
et al. 2016). In contrast to many other methods of predicting species distribution, CLIMEX includes a global meteorological database and process-based algorithms, which make it more reliable and accurate than regression-based models when projecting a species' potential distribution into novel climates (Kriticos et al. 2015a). In the present study, data on the developmental biology of T. japonicus and records of its current global distribution were used to develop a CLIMEX niche model to estimate the potential global distribution of $T$. japonicus. The model was then used to predict the potential distribution of $T$. japonicus within New Zealand and to assess potential environmental risks by comparison with the known distribution of non-target host species.

\section{Materials and methods}

\section{Outline of the CLIMEX model}

CLIMEX is a dynamic model that integrates the weekly growth responses of a population to climate and calculates a series of weekly and annual indices that allow the potential distribution of a species based on these calculations to be estimated (Kriticos et al. 2015a). Using ecophysiological parameters and meteorological data, CLIMEX uses an annual growth index $\left(\mathrm{GI}_{\mathrm{A}}\right)$ to describe the potential for population growth as a function of soil moisture and temperature during favourable conditions, and up to eight stress indices (heat, cold, wet, dry stresses and their interactions) to simulate the ability of the population to survive unfavourable conditions (Kriticos et al. 2015a). The annual growth index, $\left(\mathrm{GI}_{\mathrm{A}}\right)$, is calculated using:

$\mathrm{GI}_{\mathrm{A}}=\frac{100}{52} \sum_{\mathrm{w}=1}^{52}\left(\mathrm{TI}_{\mathrm{W}} \times \mathrm{MI}_{\mathrm{W}}\right)$

where $\mathrm{w}$ is the week of the year, $\mathrm{TI}_{\mathrm{W}}$ the temperature index for week $\mathrm{w}$, and $\mathrm{MI}_{\mathrm{W}}$ the moisture index for week w.

CLIMEX also includes a mechanism for defining the minimum annual developmental heat sum (degreedays above the base temperature for development; PDD) during the growing season that is necessary for individual development and hence population persistence. This parameter is used to calculate the potential number of generations per year and may also act as a limiting condition when a minimum of one generation needs to be completed for the species to survive in a determined location. To complete a generation, the species must experience the number of growing degree-days set for PDD (Kriticos et al. 2015a). Once the growth and stress indices are calculated weekly, they are combined to generate an overall annual index of climatic suitability, the Ecoclimatic Index (EI). This index provides an overall measure of the climatic suitability of a given location to support a permanent population of the species (Kriticos et al. 2015a). EI is calculated from:

$\mathrm{EI}=\mathrm{GI}_{\mathrm{A}} \times \mathrm{SI} \times \mathrm{SX}$

where $\mathrm{GI}_{\mathrm{A}}$ is the annual growth index, $\mathrm{SI}$ is the total stress and SX is the interaction between stresses.

The EI ranges from 0 to 100 , with these limits respectively describing unsuitable and optimal conditions for survival of the species. However, maximum values are rare and only occur in highly stable environments, such as those found near the equator (Kriticos et al. 2015a) or those created artificially in incubators (Legaspi and Legaspi 2010). In practice, EI values greater than 20 have been demonstrated to be able to support substantial population densities (Sutherst 2003; Kriticos et al. 2015a). The classification of EI used here was: unsuitable $(\mathrm{EI}<1)$, marginal $(\mathrm{EI}=1-10), \quad$ moderate $\quad(\mathrm{EI}=11-15), \quad$ high $(\mathrm{EI}=16-25)$ and optimal suitability $(\mathrm{EI}>25)$.

\section{Location records of $T$. japonicus}

Data describing the native distribution of $T$. japonicus were compiled from GPS records available on the Hymenoptera Online database (Cora et al. 2017). Information from the most recent records in the US was retrieved from both the Hymenoptera Online database (Cora et al. 2017) and published papers (Talamas et al. 2015; Jentsch 2016; Milnes et al. 2016; Ferro 2017).

CLIMEX model parameters and meteorological data

Using the 'Compare Locations' module, parameter values (Table 1) were determined: (i) from experimental data on the thermal requirements of the species, which were obtained from the literature ( $\mathrm{Li}$ and Liu 2004; Qiu et al. 2007), and by (ii) fitting the projected distribution to known observations of $T$. 
Table 1 CLIMEX parameter values used for modelling the potential distribution of T. japonicus

\begin{tabular}{|c|c|c|c|}
\hline Parameter & Description & Values & Units $^{\mathrm{a}}$ \\
\hline \multirow[t]{4}{*}{ Moisture } & SM0 = lower soil moisture threshold & 0.1 & \\
\hline & SM1 = lower optimum soil moisture & 0.4 & \\
\hline & SM2 = upper optimum soil moisture & 1.2 & \\
\hline & SM3 = upper soil moisture threshold & 1.6 & \\
\hline \multirow[t]{4}{*}{ Temperature } & DV0 = lower threshold & 12 & ${ }^{\circ} \mathrm{C}$ \\
\hline & DV1 = lower optimum temperature & 27 & ${ }^{\circ} \mathrm{C}$ \\
\hline & DV2 = upper optimum temperature & 30 & ${ }^{\circ} \mathrm{C}$ \\
\hline & DV3 = upper threshold & 34 & ${ }^{\circ} \mathrm{C}$ \\
\hline \multirow[t]{4}{*}{ Cold stress } & TTCS $=$ cold stress temperature threshold & -18.3 & ${ }^{\circ} \mathrm{C}$ \\
\hline & THCS $=$ temperature threshold stress accumulation rate & -0.0015 & Week $^{-1}$ \\
\hline & DTCS $=$ degree-day cold stress threshold & - & \\
\hline & DHCS $=$ degree-day cold stress accumulation rate & - & \\
\hline \multirow[t]{4}{*}{ Heat stress } & TTHS $=$ heat stress temperature threshold & 34 & ${ }^{\circ} \mathrm{C}$ \\
\hline & THHS = temperature threshold stress accumulation rate & 0.055 & Week $^{-1}$ \\
\hline & DTHS $=$ degree-day heat stress threshold & - & \\
\hline & DHHS = degree-day heat stress accumulation rate & - & \\
\hline \multirow[t]{2}{*}{ Dry stress } & SMDS $=$ soil moisture dry stress threshold & 0.1 & \\
\hline & $\mathrm{HDS}=$ stress accumulation rate & -0.01 & Week $^{-1}$ \\
\hline \multirow[t]{2}{*}{ Wet stress } & SMWS $=$ soil moisture wet stress threshold & 1.6 & \\
\hline & $\mathrm{HWS}=$ stress accumulation rate & 0.0065 & \\
\hline \multirow[t]{3}{*}{ Hot-wet stress } & TTHW = temperature threshold for hot-wet stress & 27 & ${ }^{\circ} \mathrm{C}$ \\
\hline & MTHW = soil moisture threshold for hot-wet stress & 1.4 & \\
\hline & PHW $=$ hot-wet stress accumulation rate & 0.0024 & Week $^{-1}$ \\
\hline Threshold heat sum & $\mathrm{PDD}=$ number of degree-days above DV0 needed to complete one generation & 175 & ${ }^{\circ} \mathrm{C}$-Days \\
\hline
\end{tabular}

${ }^{a}$ Values without units are dimensionless indices. The role and meaning of these parameters are described in Kriticos et al. (2015a)

japonicus in China, Japan and Russia (Cora et al. 2017). The CliMond global 10 min gridded climate dataset described in Kriticos et al. (2012) was used to fit parameter values. This dataset includes 30-year averages of monthly values of minimum and maximum air temperature, $\mathrm{RH}$ recorded at $9 \mathrm{~h} 00$ and $15 \mathrm{~h} 00$, and monthly rainfall total $(\mathrm{mm})$. A higher resolution climate dataset (5 min gridded-HadCM3), which is available at the database of 'CLIMEX models and projections for New Zealand' website (http://www.b3. net.nz/climenz/), was used for mapping results for New Zealand.

\section{Growth indices}

Temperature index Dissections conducted on parasitized $H$. halys eggs as part of studies on thermal development of $T$. japonicus (Li and Liu 2004) reported that $T$. japonicus eggs can hatch successfully at $15{ }^{\circ} \mathrm{C}$ but cannot complete development (no adults emerge) at this constant temperature. Qiu et al. (2007) estimated that the limiting low temperature threshold for development was $12.2^{\circ} \mathrm{C}$, which was calculated using experimental data from $T$. japonicus development at temperatures ranging from 18 to $30^{\circ} \mathrm{C}$. Additionally, $\mathrm{Li}$ and Liu (2004) and Qiu et al. (2007) reported that $T$. japonicus developed normally at temperatures ranging from 18 to $33^{\circ} \mathrm{C}$, and optimal temperatures for development of $T$. japonicus were between 27 and $30{ }^{\circ} \mathrm{C}$, where $100 \%$ of eggs hatched (Li and Liu 2004). Development of $T$. japonicus started to drop rapidly as temperatures rose above $33{ }^{\circ} \mathrm{C}$, and no parasitoids were observed to have enclosed from eggs reared at $36{ }^{\circ} \mathrm{C}(\mathrm{Li}$ and Liu 2004). Therefore, temperature index parameters were set as DV0 $=12{ }^{\circ} \mathrm{C}, \quad$ DV1 $=27{ }^{\circ} \mathrm{C}$, DV2 $=30{ }^{\circ} \mathrm{C}$ and DV3 $=34{ }^{\circ} \mathrm{C}$. 
Moisture index SM parameters are the soil moisture indices for population growth of a species. SM0 and SM3 are the limiting low and high index respectively, at below or above which no population growth takes place. SM0 was set to 0.1 to approximate permanent wilting point, which allowed population growth in the driest months (December-February) in Beijing (China). SM3 was set to 1.6 to fit the wettest locations were $T$. japonicus has been reported in southern China (e.g. wettest months in Guangzhou). SM1 and SM2 are the lower and upper optimal index, and they were set to 0.4 and 1.2 respectively.

PDD Trissolcus japonicus is expected to potentially have up to ten generations per year in Beijing, China (Qiu et al. 2007). We set the thermal accumulation parameter (PDD) to 175 degree-days to allow close to ten generations per year in Beijing, China, which is where most of $T$. japonicus current presence records have been registered (Cora et al. 2017). The base temperature was set at $12{ }^{\circ} \mathrm{C}$ (DV0).

\section{Stress indices}

Cold stress Populations of T. japonicus have been found to survive at colder temperatures than those reported for H. halys (Nystrom Santacruz et al. 2017). The cold stress threshold (TTCS) was adjusted and set to $-18.3{ }^{\circ} \mathrm{C}$ taking into account the cold tolerance observed for this species, where T. japonicus mortality has been registered to start at temperatures ranging from -17.36 to $-20.03{ }^{\circ} \mathrm{C}$ (Nystrom Santacruz et al. 2017). The accumulation rate (THCS) was iteratively adjusted to allow $T$. japonicus to barely persist in Aktach, southern Siberia, Russia (Cora et al. 2017), which is the coldest location where $T$. japonicus has been reported in Asia.

Heat stress The heat stress threshold (TTHS) was estimated and set to $34{ }^{\circ} \mathrm{C}$ based on the developmental studies conducted by $\mathrm{Li}$ and Liu (2004), and the accumulation rate (THHS) was iteratively adjusted to fit the hottest locations known to be suitable for $T$. japonicus within its humid-subtropical distribution in China and Japan.

Dry stress The limiting dry stress parameter (SMDS) was set to 0.1 to match the lower soil moisture threshold (SM0). Soil moisture related stresses are likely to begin at the same soil moisture levels where plant growth stops. As plant hosts stop growing when the soil moisture drops below permanent wilting point, this is likely to impact the populations of $H$. halys and other pentatomid hosts, and hence affect $T$. japonicus.

Wet stress According to the subtropical known distribution of $T$. japonicus in Japan, wet stress threshold (SMWS) and its accumulation rate (HWS) were adjusted to allow persistence in all current distribution records, within Japan, presenting a humidsubtropical climate.

Hot-wet stress The hot-wet stress parameters (TTHD, MTHD) and the related accumulation rate (PHD) were adjusted to allow persistence of $T$. japonicus in its known range within areas with a humid-subtropical climate in Japan and China, and thus to preclude expansion into more tropical climates within south-east Asia.

Model validation

After fitting the parameters to known records of $T$. japonicus within China, Japan and Russia, the model was then validated by overlaying the projected CLIMEX distribution model obtained and the known occurrences in geographical areas not used for parameter fitting in its native range (i.e. South Korea, and Taiwan), and also in its most recent adventive range in the USA.

Potential distribution overlap of $T$. japonicus with non-target species and $H$. halys in New Zealand

The potential overlap in the distribution of $T$. japonicus with that of New Zealand's pentatomid fauna, and also with the predicted distribution of $H$. halys (Kriticos et al. 2017), was assessed by overlaying the projected CLIMEX distribution model obtained for $T$. japonicus with the current known distribution of New Zealand's non-target species, and with that of predicted by Kriticos et al. (2017) for H. halys respectively. Nine non-target Pentatomidae species were examined. Of these, Cermatulus nasalis nasalis Westwood, C. nasalis hudsoni Woodward, and Oechalia schellenbergii Guérin are predatory in the 
subfamily Asopinae, and Hypsithocus hudsonae Bergroth, Monteithiella humeralis Walker, Dictyotus caenosus Westwood, Glaucias amyoti Dallas, Cuspicona simplex Walker, and Nezara viridula Linnaeus are phytophagous in the subfamily Pentatominae (Larivière 1995). Four of these species (C. simplex, $D$. caenosus, $M$. humeralis and $N$. viridula) are considered to have been introduced into New Zealand (Larivière 1995). The rest are considered to be either endemic (C. nasalis hudsoni and H. hudsonae) or native to New Zealand (C. nasalis nasalis, G. amyoti and $O$. schellenbergii), where native pentatomid species are also known to be present in Australia (Larivière 1995). Distribution records from all nontarget pentatomid species were obtained from Larivière (1995).

\section{Results}

Predicted potential distribution

The projected global potential distribution of $T$. japonicus (Fig. 1) resulting from the parameters used in our model (Table 1) shows that most of the world's Mediterranean, temperate, and subtropical climates are climatically suitable for the establishment of $T$. japonicus. A few areas of semi-arid and also coolsubarctic climates are also projected to have mainly marginal suitability for the persistence of $T$. japonicus populations. The model also indicates that some tropical regions, mainly with a tropical savannah climate, may also be climatically suitable for $T$. japonicus.

\section{Native range}

The potential distribution of $T$. japonicus predicted by the model in its native range (Fig. 2a) is consistent with its known geographical range. The model confirmed that all areas where this species has been reported in China, Japan, Taiwan and South Korea, are climatically suitable for population persistence of $T$. japonicus. The model also projects that the parasitoid could expand its geographical range to most nearby areas with continental and subtropical climates, where most of suitable areas will range from moderate to optimal climatic suitability for the establishment of $T$. japonicus populations. The CLIMEX model also estimates that $T$. japonicus could complete close to ten generations per year in Beijing (Fig. 3). Population growth of $T$. japonicus in Beijing appears to increase from early-May until mid-August each year as a result of an increase in rainfall and rising temperatures

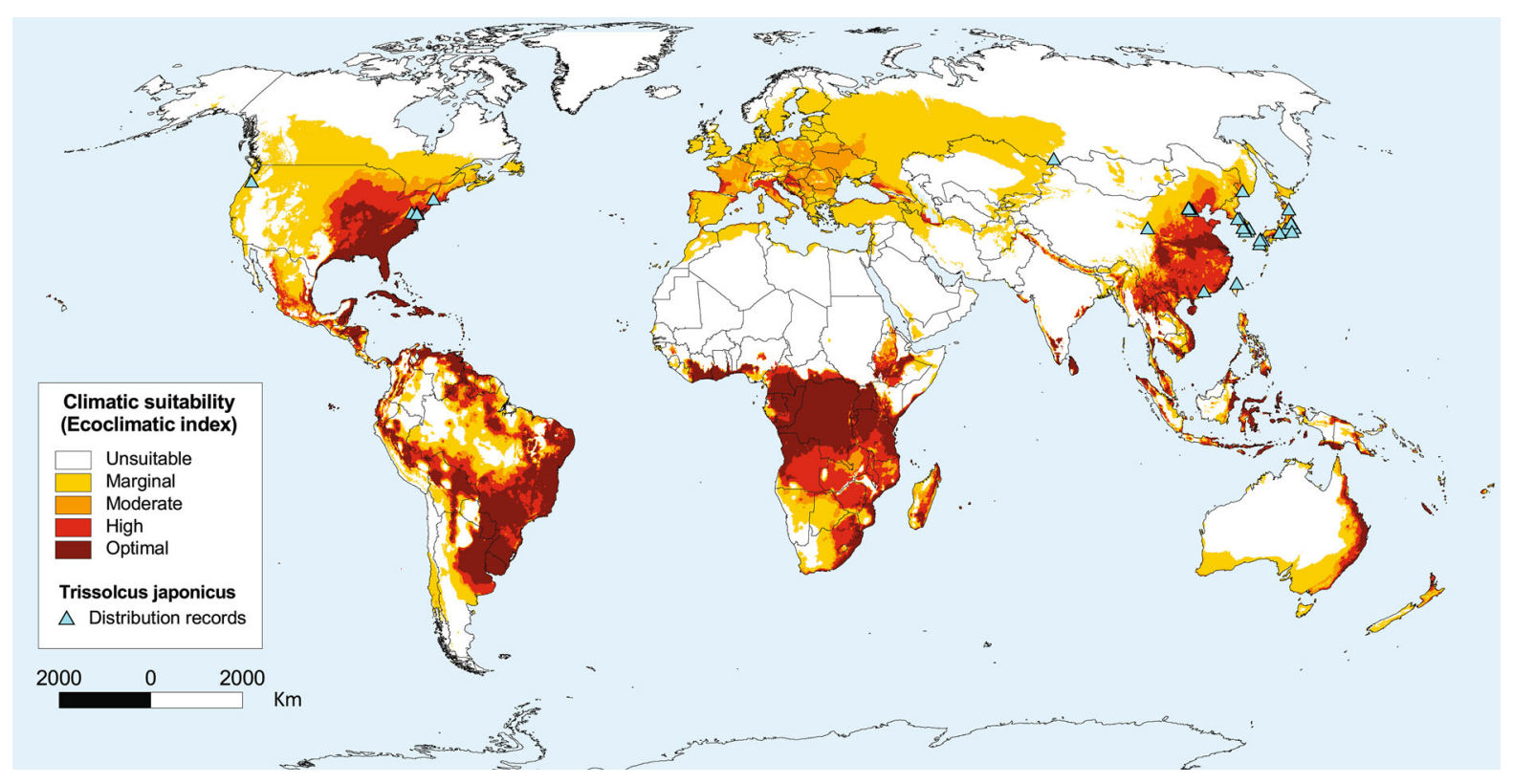

Fig. 1 Modelled global climate suitability (CLIMEX Ecoclimatic Index) for T. japonicus to persist as a permanent population. Known current distribution is shown as point locations (triangles) 
Fig. 2 Modelled climate suitability (CLIMEX

Ecoclimatic Index) for $T$. japonicus to persist as a permanent population in a its native range in Asia (China, Taiwan, South Korea and Japan) and adventive range in Russia, and in $\mathbf{b}$ its adventive range in the USA. Known current distribution is shown as point locations (triangles)

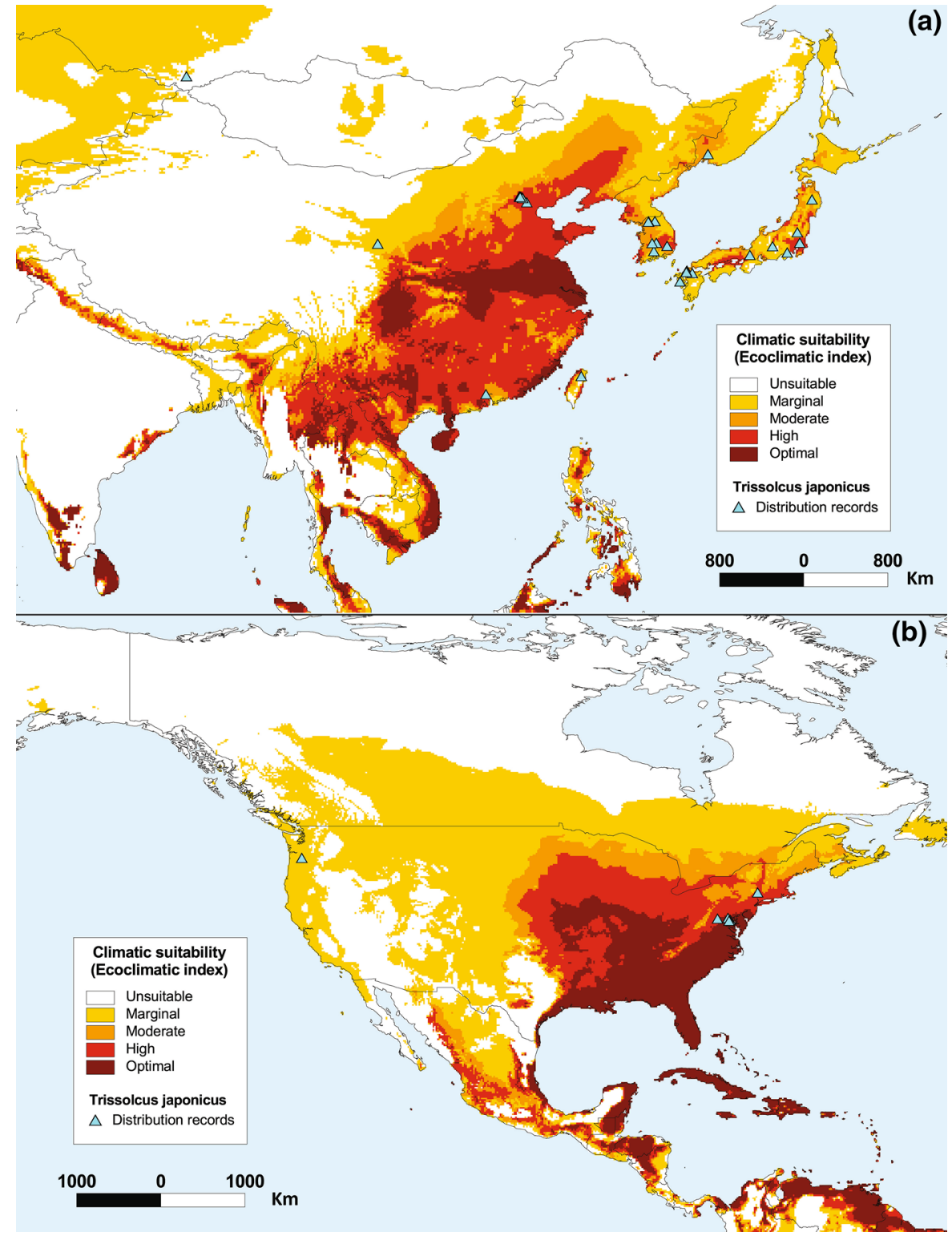

(Fig. 3). From mid-August, population growth should start dropping until late-October as a result of a sustained decrease in temperatures during these months. No population growth is expected from November to mid-March due to the dry and cold weather conditions during these months.

\section{Non-native range}

Validation of the CLIMEX potential distribution model fitted all observed non-native occurrences. All known presence records in the non-native range
(Russia and USA) are projected to be climatically suitable for the development of $T$. japonicus. In Russia only areas with humid-continental climates, including sites were $T$. japonicus has been recorded, are modelled as suitable for population persistence of $T$. japonicus, however these areas are only marginally suitable (Fig. 2a). All other regions in Russia are projected to be unsuitable for the establishment of $T$. japonicus, with the exception of small areas close to the border with China and North Korea, with a humidcontinental climate, which are projected to have marginal or moderate climatic suitability (Fig. 2a). 


\section{China,Beijing}

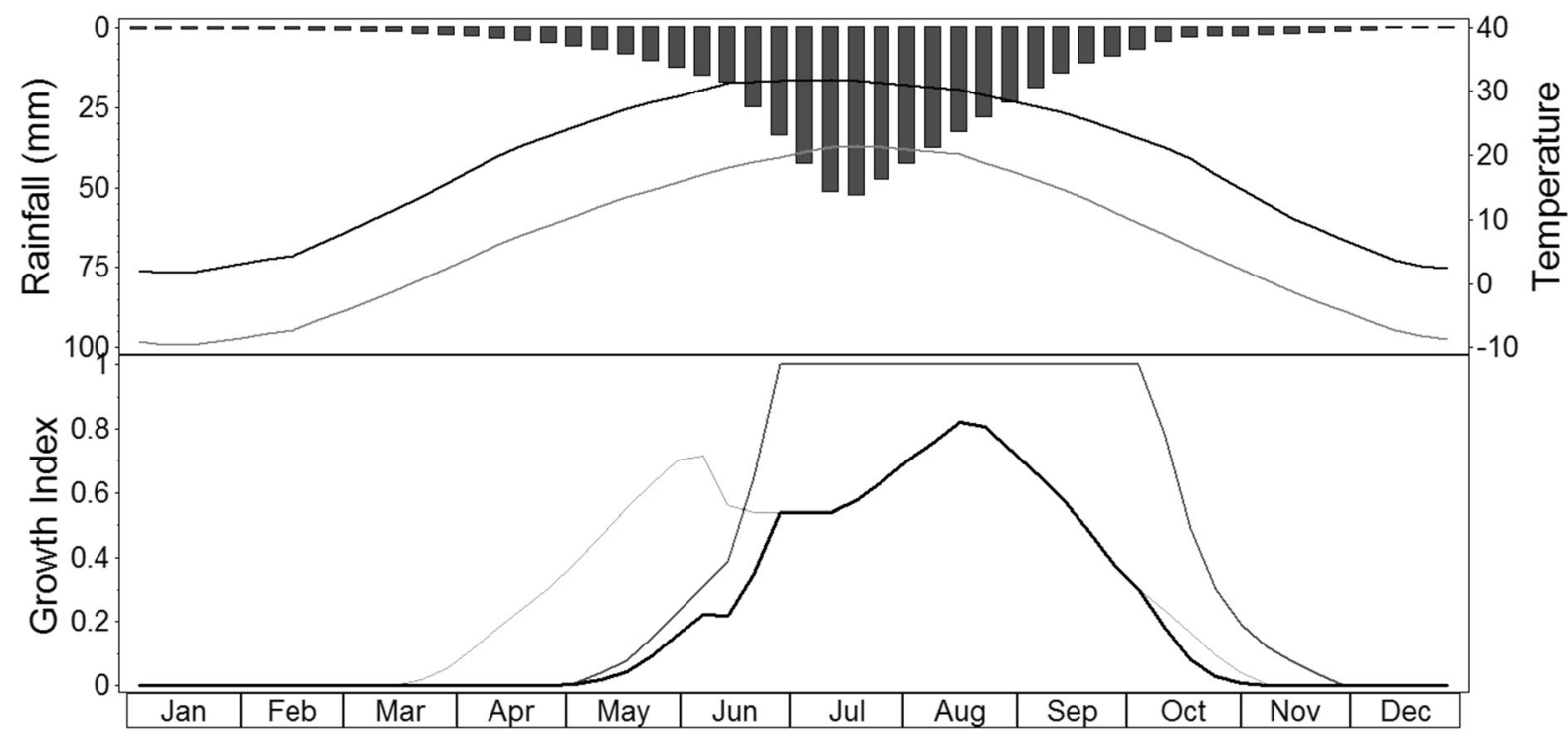

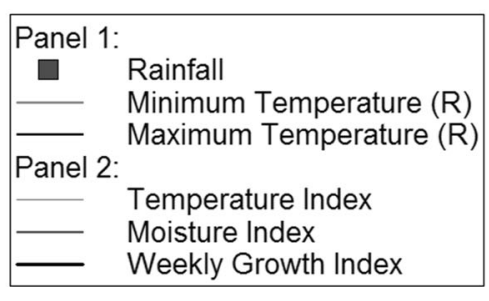

Fig. 3 CLIMEX 'compare locations' chart for T. japonicus in Beijing, China. Top panel shows weekly rainfall and maximum and minimum temperatures. Bottom panel shows CLIMEX

Most regions with subtropical and humid-continental climates in the eastern part of the USA are projected to be climatically suitable for $T$. japonicus, ranging mainly from high to optimal climate suitability (Fig. 2b). By contrast, most regions in the western parts of the USA with cold semi-arid, subarctic, and Mediterranean climates, are projected to be only marginally suitable (Fig. 2b).

\section{New Zealand}

In New Zealand, the potential distribution of $T$. japonicus covers most of the North Island and most of the northern, eastern and southern regions of the South Island (Fig. 4a), which is a much wider distribution to that of predicted by Kriticos et al. (2017) for H. halys (Fig. 4b). In the North Island, all northern regions (i.e. Northland, Auckland and Coromandel) are projected to range from moderate to high

\author{
CLIMEX - Compare Locations (1 species) \\ Trissolcus japonicus \\ Asia \\ No Climate Change / Irrigation: Not Set \\ Run on Jun 262017 16:03
}

Estimated generations per year: 10.86 growth index, temperature index and moisture index. Within chart reports the estimated generations per year for $T$. japonicus

climatic suitability for population persistence of $T$. japonicus, whereas most of the central and southern regions (e.g. Waikato, Taranaki, Gisborne, Hawke's Bay) are projected to range from marginal to moderate suitability for T. japonicus (Fig. 4a). The CLIMEX model also estimates that $T$. japonicus could complete close to seven generations per year in Auckland compared to nearly four generations further south in Wellington (see supplementary material). Trissolcus japonicus population growth in Auckland is likely to start increasing steadily from early-September until mid-January each year as a result of rising temperatures. From mid-January population growth is predicted to remain constant until late-February, when it would start to drop slowly as a result of decreasing temperatures. The lowest population growth is expected in winter from mid-June to mid-August cold weather conditions during this season. In the South Island, most of the areas projected to be suitable for the 
(a)

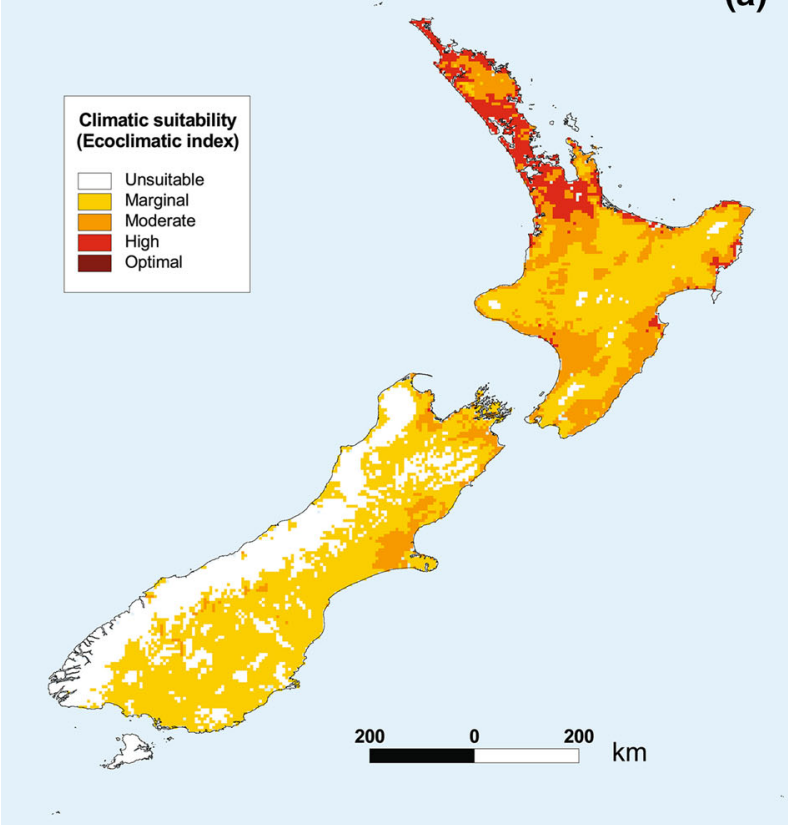

(b)

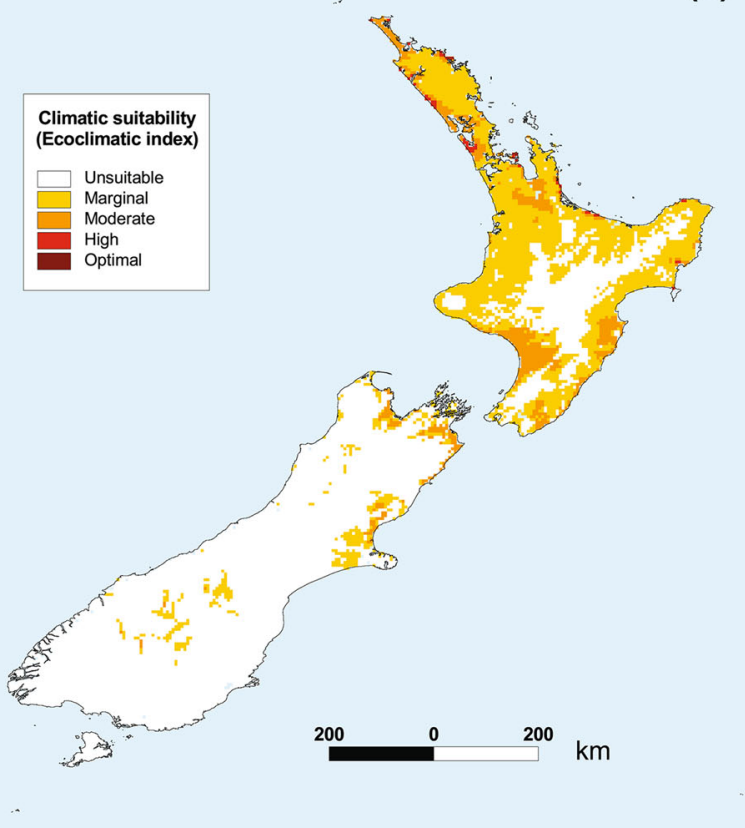

Fig. 4 Modelled climate suitability (CLIMEX Ecoclimatic Index) for a T. japonicus, based on the parameters described in Table 1, and $\mathbf{b} H$. halys, based on parameters described by Kriticos et al. (2017)

establishment of $T$. japonicus are expected to have a marginal suitability (Fig. 4a). A number of sub-alpine areas in Central Otago are estimated to be climatically unsuitable, mainly because of an inadequate annual heat sum for $T$. japonicus to complete development through one generation. Similarly, most of the West Coast region and the west side of the Southland region are projected to be unsuitable.

Potential distribution overlap with non-target species and $H$. halys in New Zealand

By overlaying the CLIMEX projected distribution for T. japonicus in New Zealand with the known distribution of New Zealand's endemic pentatomid species, H. hudsonae and C. nasalis hudsoni, an overlap can be observed in some areas of the distribution for both non-target species and that projected as suitable for $T$. japonicus (Fig. 5a). Hypsithocus hudsonae and $C$. nasalis hudsoni are known to occur only in sub-alpine regions in the South Island, and all areas where there is an overlap between the distribution of these two species and that of $T$. japonicus are projected to be either unsuitable or only marginally suitable for population persistence of $T$. japonicus (Fig. 5a). The current known distribution of New Zealand's three native pentatomid species, $C$. nasalis nasalis, $G$. amyoti and $O$. schellenbergii, appears to match most of the CLIMEX projected potential distribution for $T$. japonicus in both the North and South island. These three native pentatomids are widely distributed in the North Island, especially $C$. nasalis nasalis, and they are known to occur in a number of regions projected to have a moderate or high suitability for population persistence of $T$. japonicus (Fig. 5b). In the South Island, only $C$. nasalis nasalis is known to occur throughout the island, where it would overlap mostly with areas projected to be marginally suitable for $T$. japonicus, while G. amyoti and $O$. schellenbergii appear to be restricted to the northern parts of the South Island which are projected to range between marginal and moderate suitability for $T$. japonicus (Fig. 5b).

All four exotic pentatomid species are known to occur in both the North and South Island, and are expected to have a considerable overlap with the potential distribution for T. japonicus in New Zealand (Fig. 5c). Dictyotus caenosus is widespread in both the North and South Island and it is known to occur in a number of regions that are projected to range between 

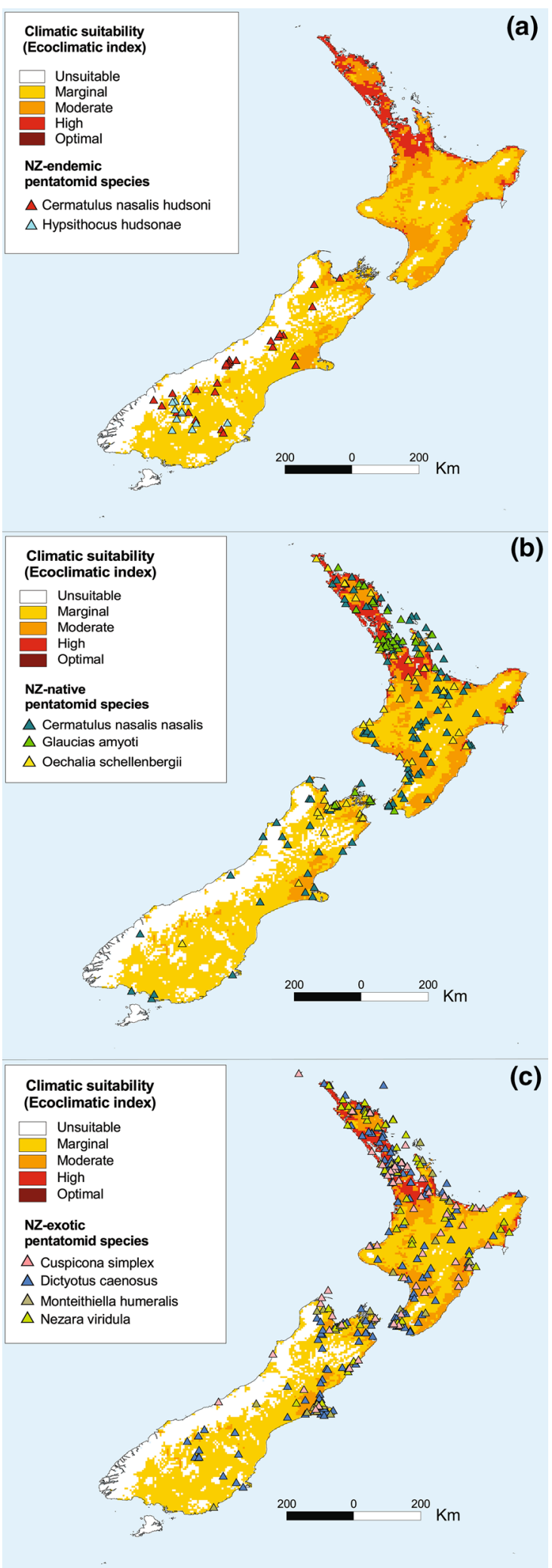

४Fig. 5 Potential overlap between the CLIMEX projected distribution for $T$. japonicus and the known distributions of a endemic, b native, and c exotic Pentatomidae species in New Zealand

marginal and high suitability for $T$. japonicus (Fig. 5c). The known distribution of $C$. simplex is expected to have an overlap with most areas projected to have a moderate or high suitability for T. japonicus in the North Island, and mostly with areas with a moderate suitability in the South Island (Fig. 5c). Both $M$. humeralis and $N$. viridula are known to occur mostly in areas projected to be marginally or moderately suitable for T. japonicus in both islands (Fig. 5c). In a scenario where the establishment of permanent populations of $T$. japonicus depended on the presence of its preferred host, $H$. halys, the potential distribution of $T$. japonicus in New Zealand would be limited mostly to the North Island and a few places in the northern and eastern parts of the South Island (Fig. 6).

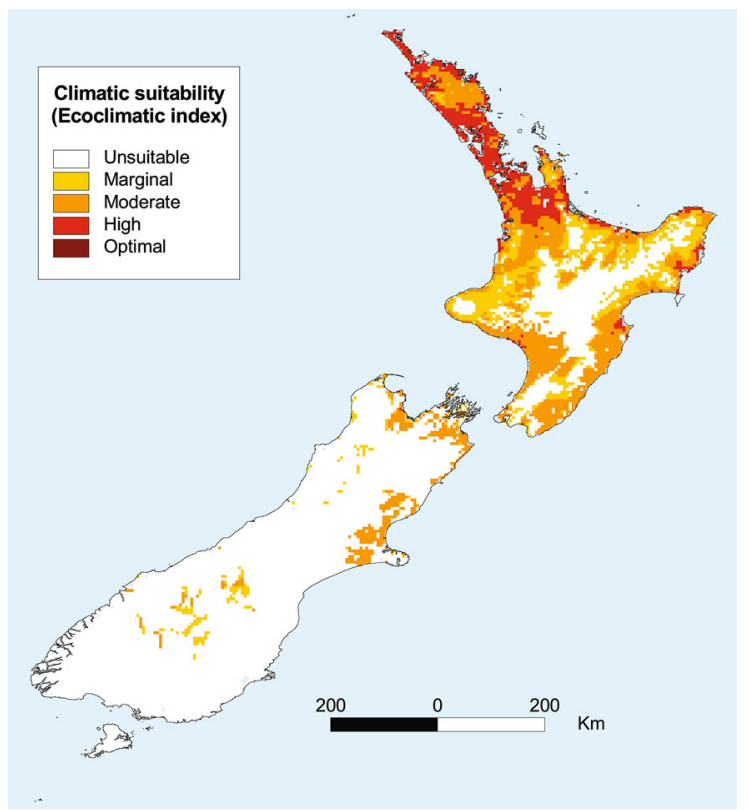

Fig. 6 Modelled climate suitability (CLIMEX Ecoclimatic Index) for $T$. japonicus to persist as a permanent population in New Zealand, resulting from the intersection of Fig. $4 a$ and $4 b$, based on the assumption that the parasitoid is likely to survive only in the presence of its preferred host $H$. halys 


\section{Discussion}

The CLIMEX model developed for $T$. japonicus agrees closely with the current known geographic distribution of the parasitoid in all countries within its native range (i.e. China, Japan, South Korea and Taiwan). It also suggests that $T$. japonicus is likely to not only have a broader distribution within those countries but also to have the potential to expand into other Asian countries with subtropical climates (e.g. Vietnam, Thailand, Laos, etc.) should suitable hosts be found there. However, the current distribution of $T$. japonicus in its native range may be underestimated due to lack of sampling, so new records within its native range and also from other countries where its preferred host, $H$. halys, is known to occur will be of use to further assess the model results. In terms of the global projected distribution of $T$. japonicus, the model accorded with the known adventive distribution records in Russia and the USA. In addition, the model suggested that $T$. japonicus would be able to survive in all temperate, Mediterranean and subtropical zones. Kriticos et al. (2017) used CLIMEX to estimate the potential distribution of $H$. halys, the main host of $T$. japonicus, estimating that this pest has the potential to substantially expand its current range in Europe and North America. Our CLIMEX model indicates that $T$. japonicus will also be able to thrive and expand in all places where $H$. halys is known to occur and also in most, if not all, areas where $H$. halys has been predicted to expand [see Kriticos et al. (2017) for global distribution maps of $H$. halys]. In the event that $H$. halys expands its range into novel areas, our model would provide potential biological control programmes using T. japonicus with valuable information to help identify climatically suitable areas for the establishment of $T$. japonicus to plan potential releases.

In New Zealand, our model indicates that suitability for population persistence of T. japonicus is expected to range between marginal and high in most of the North Island, and to be mostly unsuitable or marginal in the South Island. Trissolcus japonicus is known as a cold-tolerant species, able to survive in very low temperatures (e.g. $-20.03{ }^{\circ} \mathrm{C}$ ) (Nystrom Santacruz et al. 2017), suggesting that cold events will not be an impediment to its establishment in the colder regions of New Zealand (e.g. Central Otago). Compared to the potential distribution of its preferred host
H. halys, described in Kriticos et al. (2017), our model suggests that $T$. japonicus could have a much wider potential distribution than $H$. halys in the South Island. This is mainly because the thermal accumulation (degree-days) requirements of $T$. japonicus to complete one generation are much lower than those of $H$. halys, allowing the parasitoid to develop through many more generations than its host (Yang et al. 2009; Zhang et al. 2017).

The potential risks posed by $T$. japonicus to the non-target pentatomid species in New Zealand, based on a potential overlap between its modelled potential distribution and the known current distribution of the non-targets, varies between species. However, a number of non-climatic factors (e.g. host availability, overwintering sites, allee effects, hyperparasitoids, predators, etc.) will also affect the establishment success, survival and dispersal, and hence, the impact of $T$. japonicus on potential non-target species. For instance, most of the areas where there is an overlap between the known distributions of the endemic pentatomids $H$. hudsonae (phytophagous species) and C. nasalis hudsoni (predatory species) and that projected for $T$. japonicus, fall into areas projected as unsuitable or marginal for the survival of T. japonicus, which may initially suggest a low potential impact on these non-target species. However, the establishment of permanent populations of T. japonicus may also depend on the presence of its preferred host $H$. halys. In this scenario the potential distribution of $T$. japonicus in New Zealand would be limited mostly to the North Island and a few places in the South Island. Therefore, considering this potential scenario, the impact that $T$. japonicus may cause to $H$. hudsonae and $C$. nasalis hudsoni is likely to be nil.

Laboratory host specificity testing is commonly used as one of the key tools for biological control risk assessments (van Lenteren et al. 2003; Babendreier et al. 2005; Bigler et al. 2006), and it is important to mention that laboratory host specificity tests of $T$. japonicus with North American and European Pentatomidae species are currently being conducted in quarantine by USDA-ARS, CABI, and other laboratories (Zhang et al. 2017), and also with New Zealand Pentatomidae species by Plant and Food Research Ltd. Once laboratory host-testing data becomes available, the results presented in our study will provide with useful additional information of the potential risks posed by $T$. japonicus to non-target species, which will 
serve as a complement to laboratory host-testing results and will help to determine more accurately the risks posed to potential non-target hosts.

CLIMEX models climate suitability only (Kriticos et al. 2015a), and it does not explicitly incorporate abiotic factors such as behaviour, habitat preference, predators, host availability and overwintering sites (Baker et al. 2000; van Driesche et al. 2008), which are also important to help predict the potential geographical distributions of species (Taylor and Kumar 2012). However, most of these factors are implicit in the distribution of the species being modelled. Inferential modelling can sometimes reveal evidence of these range-modifying factors. For example, CLIMEX modelling of the native range distribution data for Essigella californica revealed evidence of the existence of biotic stress factors distinguishing the aphid's fundamental and realised niches (Wharton and Kriti$\cos 2004)$. Furthermore, the significant importance of irrigation as a pest risk-modifying factor has recently been revealed for weeds (Kriticos et al. 2015b), insects (Yonow et al. 2017) and plant diseases (Yonow et al. 2004). Sutherst (2003) recognises the limitations of any bioclimatic modelling exercise, and provides a template for explicit consideration of the effects of non-climatic factors on a species' ability to establish in a new area. Nevertheless, the present CLIMEX study has provided us with important information about the potential geographical distribution of $T$. japonicus in New Zealand and worldwide. This information can be used as a valuable guide for identifying areas to release T. japonicus, if a biological control programme should to be initiated against $H$. halys.

Acknowledgements We wish to thank Dr Darren Kriticos (CSIRO), Dr David Logan (Plant and Food Research) and Dr Jacqui Todd (Plant and Food Research) for their useful comments on draft versions of this manuscript. This work was funded in part by the Better Border Biosecurity (B3) (http:// www.b3nz.org) research collaboration, and The New Zealand Institute for Plant and Food Research Limited Strategic Science Investment Fund.

Open Access This article is distributed under the terms of the Creative Commons Attribution 4.0 International License (http:// creativecommons.org/licenses/by/4.0/), which permits unrestricted use, distribution, and reproduction in any medium, provided you give appropriate credit to the original author(s) and the source, provide a link to the Creative Commons license, and indicate if changes were made.

\section{References}

Anderson RP, Lew D, Peterson AT (2003) Evaluating predictive models of species' distributions: criteria for selecting optimal models. Ecol Model 162:211-232

Babendreier D, Bigler F, Kuhlmann U (2005) Methods used to assess non-target effects of invertebrate biological control agents of arthropod pests. BioControl 50:821-870

Baker RHA, Sansford CE, Jarvis CH, Cannon RJC, MacLeod A, Walters KFA (2000) The role of climatic mapping in predicting the potential geographical distribution of nonindigenous pests under current and future climates. Agric Ecosyst Environ 82:57-71

Bergmann E, Venugopal PD, Martinson HM, Raupp M, Shrewsbury P (2016) Host plant use by the invasive $\mathrm{Ha}$ lyomorpha halys (Stål) on woody ornamental trees and shrubs. PLoS ONE 11(2):e0149975

Bigler F, Babendreier D, Kuhlmann U (2006) Environmental impact of invertebrates for biological control of arthropods: methods and risk assessment. CABI Publishing, Wallingford

Cora JR, Johnson NF, Schneider M, Hemly SE, Musetti L, Salzberg A, Talamas EJ, Thompson JE, Anderson M (2017) Hymenoptera Online (HOL)_Trissolcus japonicus. http://hol.osu.edu/index.html?id=3249. Accessed 02 May 2017

Dhileepan K, Senaratne KADW, Raghu S (2006) A systematic approach to biological control agent exploration and prioritisation for prickly acacia (Acacia nilotica ssp. indica). Aust J Entomol 45:303-307

Duthie C (2012) Risk analysis of Halyomorpha halys (brown marmorated stinkbug) on all pathways. Ministry for primary industries. https://mpi.govt.nz/dmsdocument/2909halyomorpha-halys-brown-marmorated-stink-bug-riskanalysis-november-2012. Accessed 02 Feb 2017

Faúndez EI, Rider DA (2017) The brown marmorated stink bug Halyomorpha halys (Stål, 1855) (Heteroptera: Pentatomidae) in Chile. Arquivos Entomol 17:305-307

Ferro J (2017) Stink bug killers: scientists to release Samurai wasps. Discovery of wasps in Ulster County is likely to speed process across New York. http://www.stopbmsb.org/ more-resources/bmsb-in-the-news/stink-bug-killersscientists-to-release-samurai-wasps/. Accessed 10 May 2017

Haye T, Fischer S, Zhang J, Gariepy T (2015) Can native egg parasitoids adopt the invasive brown marmorated stink bug, Halyomorpha halys (Heteroptera: Pentatomidae), in Europe? J Pest Sci 88:693-705

Hoelmer KA, Kirk AA (2005) Selecting arthropod biological control agents against arthropod pests: can the science be improved to decrease the risk of releasing ineffective agents? Biol Control 34:255-264

Jentsch P (2016) BMSB News: the invasive parasitic wasp, Trissolcus japonicus, recently found in New York State. https://blogs.cornell.edu/jentsch/2016/09/19/bmsb-newsthe-invasive-parasitic-wasp-trissolcus-japonicus-recentlyfound-in-new-york-state/. Accessed 26 Apr 2017

Kriticos DJ, Potter KJB, Alexander NS, Gibb AR, Suckling DM (2007) Using a pheromone lure survey to establish the 
native and potential distribution of an invasive Lepidopteran, Uraba lugens. J Appl Ecol 44:853-863

Kriticos DJ, Webber BL, Leriche A, Ota N, Macadam I, Bathols J, Scott JK (2012) CliMond: global high-resolution historical and future scenario climate surfaces for bioclimatic modelling. Methods Ecol Evol 3:53-64

Kriticos DJ, Maywald GF, Yonow T, Zurcher EJ, Herrmann NI, Sutherst RW (2015a) CLIMEX version 4: exploring the effects of climate on plants, animals and diseases. CSIRO, Canberra

Kriticos DJ, Brunel S, Ota N, Fried G, Oude Lansink AGJM, Panetta FD, Prasad TVR, Shabbir A, Yaacoby T (2015b) Downscaling pest risk analyses: identifying current and future potentially suitable habitats for Parthenium hysterophorus with particular reference to Europe and North Africa. PLoS ONE 10(9):e0132807

Kriticos DJ, Kean JM, Phillips CB, Senay SD, Acosta H, Haye T (2017) The potential global distribution of the brown marmorated stink bug, Halyomorpha halys, a critical threat to plant biosecurity. J Pest Sci 90:1033-1043

Larivière M-C (1995) Cydnidae, Acanthosomatidae, and Pentatomidae (Insecta: Heteroptera): systematics, geographical distribution, and bioecology. Fauna of New Zealand 35. Manaaki Whenua Press, Lincoln

Lee D-H, Short BD, Leskey TC, Joseph SV, Bergh JC (2013) Review of the biology, ecology, and management of $\mathrm{Ha}$ lyomorpha halys (Hemiptera: Pentatomidae) in China, Japan, and the Republic of Korea. Environ Entomol 42:627-641

Legaspi BC Jr, Legaspi JC (2010) Field-level validation of a CLIMEX model for Cactoblastis cactorum (Lepidoptera: Pyralidae) using estimated larval growth rates. Environ Entomol 39:368-377

Leskey TC, Nielsen AL (2018) Impact of the invasive brown marmorated stink bug in North America and Europe: history, biology, ecology, and management. Annu Rev Entomol 63:599-618

Milnes JN, Wiman NG, Talamas EJ, Brunner JF, Hoelmer KA, Buffington ML, Beers EH (2016) Discovery of an exotic egg parasitoid of the brown marmorated stink bug Haylomorpha halys (Stål) in the Pacific Northwest. Proc Entomol Soc Wash 118:466-470

Mo J, Trevino M, Palmer W (2000) Establishment and distribution of the rubber vine moth, Euclasta whalleyi PopescuGorj and Constantinescu (Lepidoptera: Pyralidae), following its release in Australia. Aust J Entomol 39:344-350

Nystrom Santacruz E, Venette R, Dieckhoff C, Hoelmer K, Koch RL (2017) Cold tolerance of Trissolcus japonicus and Trissolcus cultratus, potential biological control agents of Halyomorpha halys, the brown marmorated stink bug. Biol Control 107:11-20

Olfert O, Haye T, Weiss RM, Kriticos DJ, Kuhlmann U (2016) Modelling the potential impact of climate change on future spatial and temporal patterns of biological control agents: Peristenus digoneutis (Hymenoptera: Braconidae) as a case study. Can Entomol 148:579-594

Potter KJB, Kriticos DJ, Watt MS, Leriche A (2009) The current and future potential distribution of Cytisus scoparius: a weed of pastoral systems, natural ecosystems and plantation forestry. Weed Res 49:271-282
Qiu L, Yang Z, Tao W (2007) Biology and population dynamics of Trissolcus halyomorphae. Sci Silvae Sin 43:62-65

Robertson MP, Kriticos DJ, Zachariades C (2008) Climate matching techniques to narrow the search for biological control agents. Biol Control 46:442-452

Saavedra MC, Avila GA, Withers TM, Holwell GI (2015) The potential global distribution of the bronze bug Thaumastocoris peregrinus Carpintero and Dellapé (Hemiptera: Thaumastocoridae). Agric For Entomol 17:375-388

Sutherst RW (2003) Prediction of species geographical ranges. J Biogeogr 30:805-816

Sutherst RW (2014) Pest species distribution modelling: origins and lessons from history. Biol Inv 16:239-256

Talamas EJ, Buffington M, Hoelmer K (2013) New synonymy of Trissolcus halyomorphae (Yang). J Hymenopt Res 33:113-117

Talamas EJ, Herlihy MV, Dieckhoff C, Hoelmer K, Buffington M, Bon M-C, Weber DC (2015) Trissolcus japonicus (Ashmead) (Hymenoptera, Scelionidae) emerges in North America. J Hymenopt Res 43:119-128

Taylor S, Kumar L (2012) Potential distribution of an invasive species under climate change scenarios using CLIMEX and soil drainage: a case study of Lantana camara L. in Queensland, Australia. J Environ Manag 114:414-422

van Driesche R, Hoddle M, Center TD (2008) Control of pests and weeds by natural enemies: an introduction to biological control. Blackwell Pub, Malden

van Lenteren JC, Babendreier D, Bigler F, Burgio G, Hokkanen HMT, Kuske S, Loomans AJM, Menzler-Hokkanen I, van Rijn PCJ, Thomas MB, Tommasini MG, Zeng Q-Q (2003) Environmental risk assessment of exotic natural enemies used in inundative biological control. BioControl 48:3-38

Watt MS, Kriticos DJ, Alcaraz S, Brown AV, Leriche A (2009) The hosts and potential geographic range of Dothistroma needle blight. For Ecol Manag 257:1505-1519

Watt MS, Kriticos DJ, Lamoureaux SL, Bourdôt GW (2011) Climate change and the potential global distribution of serrated tussock (Nassella trichotoma). Weed Sci 59:538-545

Wharton TN, Kriticos DJ (2004) The fundamental and realized niche of the Monterey Pine aphid, Essigella californica (Essig) (Hemiptera: Aphididae): implications for managing softwood plantations in Australia. Divers Distrib 10:253-262

Yang Z-Q, Yao Y-X, Qiu L-F, Li Z-X (2009) A new species of Trissolcus (Hymenoptera: Scelionidae) parasitizing eggs of Halyomorpha halys (Heteroptera: Pentatomidae) in China with comments on its biology. Ann Entomol Soc Am 102:39-47

Yonow T, Kriticos DJ, Medd RW (2004) The potential geographic range of Pyrenophora semeniperda. Phytopathology $94: 805-812$

Yonow T, Kriticos D, Ota N, van Den Berg J, Hutchison W (2017) The potential global distribution of Chilo partellus, including consideration of irrigation and cropping patterns. J Pest Sci 90:459-477

Zhang F, Chen Z, Zhang S (2000) The occurrence and control of Halyomorpha halys in kiwifruit orchards. Northwest Hortic $2: 38$

Zhang J, Zhang F, Gariepy T, Mason P, Gillespie D, Talamas E, Haye T (2017) Seasonal parasitism and host specificity of 
Trissolcus japonicus in northern China. J Pest Sci 90:1127-1141

Z-x Li, Y-s Liu (2004) Effect of temperature on development of eggs parasitoid Trissolcus halyomorphae and the eggs of its host, Halyomonrpha halys. Chin J Biol Control 20:64-66

G. A. Avila is an applied entomologist with a particular interest in biological control of forestry and crop pests. He is a scientist at the New Zealand Institute for Plant \& Food
Research in Auckland, and his current activities include improving risk assessment of candidate classical biocontrol agents pre-release.

J. G. Charles is an applied entomologist, working on IPM in fruit crops, especially by biological control. He is an honorary fellow at the New Zealand Institute for Plant \& Food Research in Auckland. 